\title{
No rastro da cobra-grande: cosmologias e territorialidades no Médio Rio Negro
}

\author{
Luiz Augusto Sousa Nascimento ${ }^{1}$ \\ Universidade Federal de São Carlos
}

Resumo: A região do rio Negro no noroeste amazônico é habitada por povos indígenas multiétnicos que compartilham uma unidade sociocultural convergente no sentido de compreender as relações diárias entre clãs, pessoas e, acima de tudo, o território. O território e os processos de territorialidade são entendidos a partir de um conjunto de elementos associados a cosmologias, pelas fisicalidades e pelas contraposiçoes do Estado. Neste contexto, a pesquisa visa compreender, a partir do ponto de vista das populações locais, as concepções que giram em torno das noções de território e processos de territorialidades por eles vivenciados. À luz da reflexão, as narrativas referentes à cobra-grande são fundamentais para compreender a construção e pertença das territorialidades locais. Como resultados, foi demonstrado uma configuração territorial rionegrina cujas bases são fundadas na trilha da cobra-grande que se opõe ao Estado, que ignora outras formas de apropriação de territórios não aqueles baseados demarcação de fronteiras rígidas pautadas na cartografia ocidental.

Palavras-chave: Populações multiétnicas; territórios; Aruak. 


\title{
In the cobra-grande trail: cosmologies and territorialities in the Middle Rio Negro
}

\begin{abstract}
The Rio Negro region in the Amazonian northwest is inhabited by multiethnic indigenous peoples who share a convergent sociocultural unity in the sense of understanding the daily relationships between clans, people and above all the territory. The territory and the processes of territoriality are understood from a set of elements associated with cosmologies, by the physicality and counterpoint of the State. In this context, the research aims to understand, from the point of view of the local populations, the conceptions that revolve around the notions of territory and processes of territorialities experienced by them. In the light of the reflection, the narratives referring to the great snake are fundamental to understand the construction and belonging of the local territorialities. As results, it was demonstrated a Rio Negro territorial configuration whose bases are based on the trail of the great snake that opposes the State that ignores other forms of appropriation of territories not those based demarcation of rigid boundaries ruled based on the western cartography.
\end{abstract}

Keywords: Multiethnic populations; territories; Aruak.

\section{En el camino de la cobra-grande: Cosmologías y territorialidades en el medio Rio Negro}

\begin{abstract}
Resumen: La región de Rio Negro en el noroeste de la Amazonía está habitada por pueblos indígenas multiétnicos que comparten una unidad sociocultural convergente para comprender las relaciones diarias entre clanes, personas y, sobre todo, el territorio. El territorio y los procesos de territorialidad se entienden a partir de un conjunto de elementos asociados con las cosmologías, por las fisicalidades y las oposiciones del Estado. En este contexto, la investigación tiene como objetivo comprender, desde el punto de vista de las poblaciones locales, las concepciones que giran en torno a las nociones de territorio y los procesos de territorialidades que experimentan. A la luz de la reflexión, las narrativas referentes a la gran serpiente son fundamentales para entender la construcción y pertenencia de las territorialidades locales. Como resultado, se demostró una configuración territorial rionegrina cuyas bases se basan en el rastro de la gran serpiente que se opone al Estado, que ignora otras formas de apropiación de territorios, no aquellas basadas en la demarcación de límites rígidos basados en la cartografía occidental.
\end{abstract}

Palabras clave: poblaciones multiétnicas; territorios Aruak. 


\section{Introdução}

A região do rio Negro é uma área de proporções demográfica, paisagística e etnograficamente significativas. Geograficamente dividida em três subáreas (Alto, Médio e Baixo), a bacia rionegrina é habitada em suas margens e interflúvios por populações indígenas multiétnicas, regionais brasileiros, colombianos, venezuelanos, militares, entre outros. Desde o século XVII, no processo de interiorização colonial na região Amazônica, uma gama de viajantes naturalistas, administradores, demógrafos, etnólogos entre outros navegaram pelo rio Negro pela região em busca de conhecimentos gerais e específicos da região, como, por exemplo, demarcação de fronteiras e a procura de riquezas naturais. Embora a região seja formada por populações multiétnicas, as histórias em torno das narrativas da cobra-grande se fazem presentes na memória coletiva local. Dessa maneira, os resultados da pesquisa que ora sublinho neste artigo estão pautados nas narrativas vinculadas à cobra-grande coletadas durante a pesquisa de campo entre os meses de agosto de 2010 a junho de $2013 .^{2}$

A referida pesquisa foi realizada no âmbito do Grupo de Trabalho - GT instituído ${ }^{3}$ pela Fundação Nacional do Índio - Funai; para realizar estudos de fundamentação antropológica para subsidiar a elaboração do Relatório Circunstanciado de Identificação e Delimitação de Terras Indígenas no Noroeste amazônico. O relatório Circunstanciado é um instrumento fundamental exigido pelo estado brasileiro para compor o processo jurídico-administrativo de homologação de terras indígenas no Brasil.

A metodologia da pesquisa centrou-se na etnografia associada à etnohistória, quando as narrativas coletadas em campo ${ }^{4}$ tiveram um papel fundamental para o nosso propósito analítico: compreender, a partir do "rastro da cobragrande", as concepções de território e suas territorialidades. Outras metodologias foram adotadas, por exemplo, oficinas de mapas utilizando exercícios de construção livres, onde os próprios indígenas representavam graficamente áreas de uso comum dos recursos naturais, a comunidade, os locais sacralizados, entre outros. Esse exercício foi de fundamental importância para compreender o conhecimento prático da dimensão territorial e os seus modos de organização social e da dinâmica territorial peculiar à área de estudo.

O artigo está organizado da seguinte maneira: na primeira seção descreveremos suscintamente, as primeiras incursões coloniais no rio Negro e as populações indígenas que se encontravam na região; seguindo com uma seção onde apresentamos as principais pesquisas etnográficas realizadas no contexto do rio Negro, bem como outras literaturas com a finalidade de demonstrar o contexto etnográfico do rio Negro e a diversidade de pesquisas realizadas. Na sequência, lançamos mão para apresentar a configuração socioespacial da bacia do rio $\mathrm{Ne}-$ gro e as suas peculiaridades, por exemplo, a mobilidade territorial flutuante e a exogamia linguística; complementando com uma seção em que considero as sociocosmologias e as populações multiétnicas como elementos fundamentais pa-

2 As narrativas referentes à cobra-grande possuem algumas variações terminológicas, por exemplo, entre os Pirapuia, Desana e Baré (cobra-grande e cobra-Honorato), entre os Tucano (cobra-canoa). Também, para os Baré, cobra-grande pode ser espírito, encantamento. Em relação às narrativas rionegrinas ver: Andrello (2005, 2006, 2012), Bruzzi (1994), Wright (1999), Chernela (2004, 1999), Barbosa Rodrigues (1890) entre otros. As narrativas a presentadas no texto foram coletadas junto as populações multiétnicas da bacia do rio Negro. (Baré, Baniwa, Piratapuia; Desana, Tariana; Tukano)

3 Portaria Ministério da Justiça No. 2.151 de 16 de dezembro de 2010.

4 Durante a pesquisa de campo, vistamos vinte e seis comunidades ao longo das calhas dos rios Padauiri, Preto, Daraha, Aracá, Curuduri, Malalahá e Demeni afluentes da margem esquerda do rio Negro 
ra a compreensão da configuração do território e, por fim, as análises das narrativas da cobra-grande e suas relações com o território.

\section{As incursões coloniais ao Rio Negro e as populações indígenas}

As primeiras referências ao rio Negro, de acordo com Santos (2013) e Freire (1999), datam dos relatos de duas expedições oriundas da Venezuela à procura do El Dourado - uma terra rica em ouro, cujo centro supostamente ficava na serra da Parima (Alto Rio Negro). Essas primeiras expedições foram comandadas respectivamente pelo espanhol Hernan Perez da Quesada em 1538 e o alemão Philipp Von Hutten em 1541. Essas viagens não lograram seus objetivos, mas encontraram populações indígenas que já viviam na região. Outros desbravadores do rio Negro são destacados pela historiografia, como o espanhol Francisco Orenalla, que no início do século XVII incursionou o rio Amazonas chegando à foz do rio Negro. Neste mesmo século, o Padre jesuíta Ignácio Szentmartonyi e Francisco Xavier Ribeiro de Sampaio realizaram expedição no rio Negro compilando uma série de dados significantes da paisagem, da geografia e das populações que habitavam a região.

A história da colonização do rio Negro apresenta pontos comuns às ocorridas, de um modo geral, em todo o Amazonas: as estratégias de conquista onde as Missões e Fortes seguiam lado a lado garantindo a expansão e dominação das fronteiras e consequentemente a exploração dos recursos naturais.

Na perspectiva socioeconômica, a interiorização colonial no rio Negro pode ser caracterizada por três situações históricas: 1) período da expansão colonial portuguesa, cujo motor foi impulsionado pelo Regimento das Missões que utilizavam vários instrumentos para captura de índios tais como o "descimento indígena"; os "Resgates"; as "Guerras Justas"; 2) o período do ciclo da borracha que promoveu uma intensa migração interna para a região e; 3) o processo de reordenamento territorial promovido pelo Estado brasileiro a partir de 1988, quando a Constituição brasileira garantiu aos povos indígenas as terras originariamente ocupadas por eles.

A região do Médio Rio Negro, de acordo com os registros dos cronistas aqui pesquisados, começa a ser colonizada a partir do primeiro quartel do século XVII, sobretudo com os portugueses que adentravam o rio e os interflúvios com o objetivo de capturar indígenas para servirem como escravos, cujos propulsores estavam fundados no "descimento indígena", quando milhares de índios foram retirados de suas malocas de origem, transferidos de seus territórios e integrados ao chamado sistema de "aldeias de repartição" ou "aldeia doméstica". Nessa circunstância, os índios paradoxalmente eram considerados "livres", perfeitamente inseridos na produção e prestação de serviços, com permissão legal da Coroa portuguesa.

Ao longo de mais de três séculos de encontros intersocietários oriundos da investida colonial, as populações ${ }^{5}$ multiétnicas que foram se configurando às margens do rio Negro e seus afluentes mantêm uma longa história de contato, marcada sempre pela exploração e conflitos, no entanto, sem perder suas bases sociocosmológicas como referência para pensar seus mundos. Os períodos sub-

5 De acordo com Meira (1990), boa parte da população falante de nheengatu e habitante do médio e baixo rio Negro integrou a população indígena refugiada nas cabeceiras dos rios envolvida compulsoriamente na rede de aviamento que iria se fortalecer ainda mais no período áureo da borracha. (Meira, 1990, p. 27) 
sequentes até os finais dos anos de $1980^{6}$, os indígenas habitantes da bacia do rio Negro conviver com agentes sociais múltiplos (militares, missionários, patrões, regatões, funcionários do governo, etc.) sob uma política de submissão e semiescravidão, onde os indígenas perdiam a sua autonomia quanto sujeito político.

Os conflitos antes centrados na escravização de indígenas, pela imposição missionária de trazer um Deus cristão para salvar as almas dos "selvagens" e pela forte influência dos comerciantes que usurpavam o trabalho dos "gentis", ganhava novos elementos, quando as questões relacionadas ao território passam a fazer parte de uma pauta ampla com vários agentes em disputas, inclusive, o Estado, antigo "tutor" dos índios.

A falta de entendimento sobre o território é atenuante nos dias atuais. As populações indígenas estão mobilizadas para defender seus respectivos territórios, no entanto, procuram se afastar dos pressupostos fundamentados pelo Estado, por entender que que todo o território da bacia do rio Negro já havia sido demarcado pelos seus demiurgos. Essa demarcação ancestral é visivelmente explícita nas suas sociocosmologias que são muito bem fundamentadas em metáforas empregadas por alguns anciões que ignoram a escrita, o papel do "branco":

Nossa história não está no papel, está na pedra, na serra, no marara, na cabeça de cada um de nós. Nosso Deus nem sabia o que era papel, lápis. O que está em nossas cabeças nunca apodrece, o papel apodrece, mas a nossa memória não apodrece. Assim conhecemos bem nosso lugar, nossas malocas, nossas roças. O rio Negro está em desenhado em nossa cabeça. (Braz França Baré, comunicação pessoal, comunidade Canafé, rio Negro, setembro de 2012)

A posição do ancião baré, nos faz refletir sobre o papel das narrativas quanto à visualização do território e os processos de territorialidades que as populações indígenas rionegrinas vivenciaram e vivenciam. Apesar de variações quanto ao pensamento do ancião, as narrativas dos povos indígenas do rio Negro compartilham, de modo geral, uma estrutura concêntrica, no sentido da constância em outros eixos narrativos. Embora manejada por povos diferentes, percebe-se que cada grupo reelabora suas versões, produzindo eixos particulares e interpretando de acordo com as suas respectivas posições específicas no contexto rionegrino. Veremos mais adiante, o quanto as narrativas exercem orientações cotidianas no contexto estudado.

\section{A etnologia e outras literaturas}

Nesta seção, a ideia é apresentar o cenário etnográfico do rio Negro quanto a sua diversidade de pesquisas que já foram realizadas, dando ênfase às pesquisas etnológicas e a literatura historiográfica dos cronistas e administradores coloniais, no entanto, não nos propomos a debater exaustivamente toda produção, mas lançar luz sob a importância dessas pesquisas para os insights que corroboraram para a elaboração do presente artigo.

\footnotetext{
${ }^{6} \mathrm{O}$ ano de 1980 é um marco fundamental para as populações locais, pois é o ano em que são desativados os internatos salesianos. Os internatos salesianos foram instalados na região na década de 1940, onde boa parte dos indígenas passaram a estudar e morar, tendo como obrigação deixar de falar suas respectivas línguas maternas e alguns rituais visto pela igreja como demoníaco. (Ver ANDRELLO, 2004, 2010; MEIRA; 2004; NASCIMENTO, 2017)
} 
A literatura etnológica, etnográfica, histórica, historiográfica e arqueológica7 da região em tela é bem diversificada (cronistas, missionários, administradores, naturalistas, entre outros), abrangendo estudos de diversas vertentes do pensamento teórico.

Os trabalhos dos cronistas La Condamine (1992 [1745]); Ferreira ([1792]1983); Stradelli 1887 (2009); e dos naturalistas Wallace ([1853]1982) e Spix \& Martius ([1817]1981), centraram-se em análises que desconsideram o ponto de vista das populações locais, considerando como foco prioritário, os preceitos de um conhecimento cientificista e de uma visão, a partir do ponto de vista do colonizador. Nessa mesma linha de pensamento segue os trabalhos de Noronha (1856), Moraes Filho (1882), esses dois últimos, apresentaram detalhes da localização dos povos indígenas na região, principalmente os Manaos, Passé e Baré, estes os que se apresentam maiores registros entre os pesquisadores acima citadas. As consultas às referidas obras foram de fundamental importância para entender os povos do passado e presente que habitavam-habitam o contexto etnográfico em tela, bem como para confirmar o etnocídio de um número significativos de povos indígenas.

As abordagens de cunho etnográfico são bem diversificadas. As primeiras pesquisas de antropólogos estiveram vinculadas a teoria da aculturação KochGrunberg ([1907], Reichel-Dolmatoff (1971)2010), Galvão (1955, 1979), Adália (1977), Nimuendajú (1983), que estavam interessados em cultura material, bem como em identificar as perdas culturais e diagnosticando a situação em que cada grupo se encontrava. A partir da segunda metade do século XX, as análises da sociocosmologia, da cosmopolítica e estudos voltados para compreender a estrutura e organização social ganham destaques nas pesquisas dos etnólogos contemporâneos. Nesse rol incluem as pesquisas de S. Hugh-Jones (1979, 2012), C. Hugh-Jones (1979), Goldmam (1968), Wright (1988, 1992, 1996, 1999), Bruzzi (1994), Charnela (2004), Hill (1988), Oliveira (1991), Andrello (2004, 2010), Lasmar (2004), Melo (2009), Cabalzar (2010), Maia Figueiredo (2009), Nascimento $(2014,2017)$. Nas últimas décadas houve bastante interesse à abordagem da antropologia política Pérez (1988), Meira (1994), Peres (2004, 2009, 2014), Pereira (2007), que vinculam suas pesquisas para as análises das situações históricas de ocupação populacional da bacia do rio Negro para os processos sociais e a relação do Estado no mundo indígena.

$\mathrm{Na}$ atualidade, as pesquisas na região do rio Negro seguem atraindo uma gama de pesquisadores que se debruçam em abordagens bem diversificadas. Destacam-se as pesquisas realizadas pelos próprios indígenas8, que auxiliados por mediadores externos começaram a produzir seus próprios textos reflexivos, com destaque para o compilado das narrativas rionegrinas organizado pelo Instituto Socioambiental - ISA, coordenados pelo antropólogo Geraldo Andrello e outros associados ao ISA. Outrossim, uma série de monografias, dissertações e teses defendidas por alunos indígenas em universidades regionais, como também fora do eixo amazônico.

As orientações teóricas que procuramos dialogar são aquelas cujas análises giram em torno da importância das cosmosociologias para compreender o pensamento ameríndio (HUGH-JONES, 1979; WRIGHT, 1999; ANDRELLO, 2014) bem como aquelas que enfatizam a importância do "ponto de vista do nativo"

7 Estudos arqueológicos Neves (1994), Vidal (1999), indicam que os índios já habitavam a área em 1.200 A.C. Entretanto, não há confirmação de vínculos entre esses antigos ocupantes e os indígenas que atualmente habitam a região.

${ }^{8}$ Destacam-se Américo Castro Fernandes (Diakuru), Dorvalino Moura Fernandes (Kisebi), Moises Maia (Akito), Tiago Maia (Ki’mâro) entre outros. Esses autores compõem a coleção "Narradores Indígenas" organizada pelo Instituto Socioambiental - ISA. 
para a elaboração de etnografias que valorizar a polifonia e os saberes locais como base analítica e reflexiva de construções de conhecimentos. (LASMAR, 2004; CABAZAR, 2010; ANDRELLO, 2010, NASCIMENTO, 2017, JUNIOR FELIPE, 2018)

\section{Configuração socioespacial da região do Médio Rio Negro}

As populações indígenas na região em estudo se organizam socialmente em comunidades multiétnicas ${ }^{9}$, marcadas por dinâmicas de mobilidades socioespaciais e pela exogamia linguística. Andrello (2004, p. 132) analisa a configuração multiétnica da região considerando que: "uma quantidade enorme de famílias indígenas que seriam deslocadas para o trabalho nos seringais". Essa é a razão pela qual até os dias de hoje encontramos em toda extensão do médio rio Negro e os afluentes, bem como boa parcela do baixo curso, muitas famílias indígenas cujos antepassados são originários dos rios Uaupés, Içana e Xié. Essas populações passaram por diferentes situações históricas, porém a maioria delas associada ao avanço da colonização para o domínio territorial; o controle do monopólio dos recursos naturais e a perseguição aos povos locais, através dos resgates, das guerras justas ou mesmo pela força dos comerciantes, que de maneira geral, usava a lei e os aparatos de repressão do Estado aos seus benefícios, sobretudo, aliciar indígenas para mão-de-obra dos seus empreendimentos. (WRIGHT, 1999; ANDRELLO, 2004; 2006; NASCIMENTO, 2017).

O Médio Rio Negro compreende os municípios de Barcelos e Santa Isabel do Rio Negro, a junção demografia destes dois municípios corresponde a uma extensão territorial de mais de 185 mil km² $^{2}$ e uma população de mais de quarenta mil habitantes.

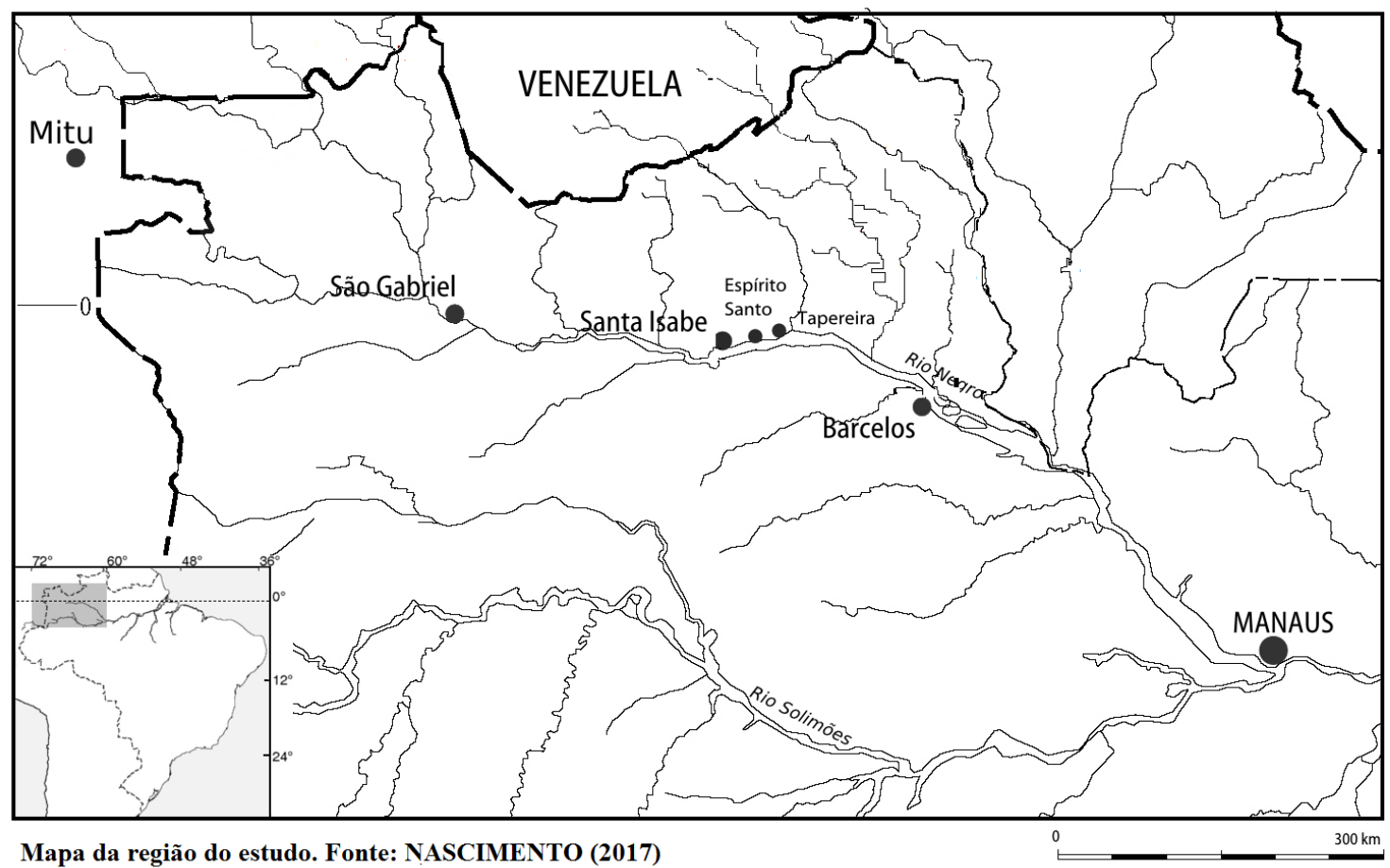


O município de Santa Isabel do Rio Negro, antiga Tapuruquara, soma 62.846.382 $\mathrm{km}^{2}$ em seu território e 18.146 habitantes, considerando a população urbana e do interior, segundo Censo Demográfico do IBGE de 2010. Dentro das fronteiras do município, além da sede municipal, existem nove malocas yanomami e, outras quarenta e duas comunidades e, cerca de 500 sítios. Cada comunidade forma uma unidade sócio-política autônoma, com seus próprios "administradores" - um tipo de capitão ou tuxaua. Entre as comunidades, há um consenso na divisão das áreas de uso destinadas ao cultivo de roças e a construção de moradias para cada família residente. Há, no entanto, lagos, igarapés e paisagens de recursos (piaçaba, castanhal, bacabal, açaizal, entre outras) de uso compartilhado entre moradores de comunidades vizinhas.

As populações das comunidades são majoritariamente indígenas, formadas por famílias de outras localidades do rio Negro, principalmente do Alto e que se dizem pertencer à própria região. A configuração populacional é o resultado de uma longa história de contato dos grupos indígenas do rio Negro com diferentes agentes da colonização: missionários católicos e protestantes, militares, comerciantes e trabalhadores oriundos de outras regiões do Brasil, que migraram para trabalhar nas "empresas" de balata, seringa, castanha, piaçaba e outros produtos. Esses fatores imprimem à Santa Isabel do Rio Negro, uma dinâmica socioeconômica cujo propulsor se constituir em espaços e paisagens que tangenciam ou estão em sobreposição às terras indígenas e áreas de preservação ambiental, como por exemplo, a APA de Tapuruquara.

Uma das características do município de Santa Isabel do Rio Negro é o fato de grande parte de seu território estar sob a proteção ambiental, através da criação e delimitação da “Área de Proteção Ambiental de Tapuruquara”, em 10 de setembro de 2001. Esta iniciativa, de acordo com o decreto municipal, considerou o fato de que em 1997, o Ministério do Meio Ambiente definiu que 80\% do território do seria considerado de "extrema importância para conservação e uso sustentável" e que o mesmo constitui "zona de contato entre várias fisionomias vegetais amazônicas, gerando alta diversidade biológica”, e ainda que a área municipal "abriga um considerável número de espécies ameaçadas ${ }^{10}$ ".

Barcelos, mais antiga que Santa Isabel, conhecida também pelo seu nome antigo, Aldeia de Mariuá, foi fundada em 1728, tornando-se a primeira sede da capitania de São José do Rio Negro. Atualmente, o município compreende uma

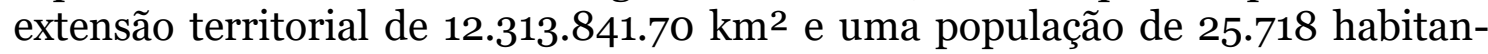
tes, considerando o centro urbano e o interior. Vale ressaltar que Barcelos é o segundo maior município do Brasil, sendo menor em área apenas para o município de Altamira no Pará com 159.695,938 km².

A demografia territorial de Barcelos é bastante extensa, todavia, uma pequena parte de terras está destinada às Unidades de Conservação, Área de Proteção Ambiental e Terras Indígenas que correspondem a trinta e oito de percentagem da extensão territorial do município. Esse contexto vem arrolando uma série de questão às populações indígenas locais que concerne ao território, a identidade, a invisibilidade dos indígenas como sujeitos produtores de conhecimentos e que como qualquer outra sociedade humana, dinamiza "culturas".

Nos últimos anos, a região do Médio Rio Negro tornou-se um ambiente hostil para com os indígenas. No ano de 2000 quando o Estado brasileiro oficializou a constituição do Grupo de Trabalho para realizar estudos antropológicos de identificação e demarcação de terras indígenas, ocorrem movimentos bastan- 
tes contrários a tal inciativa, sobretudo por parte de pessoas associadas ao turismo esportivo, à pesca comercial e dos patrões da piaçaba.

Desde então, eclodiram movimentos contrários aos procesos de demarcação de terras para populações indígenas, acentuado ódio excessivo para como essas populações. Parte da população local não indígena contrapõe alegando a falta de indianidade por parte da população do interior, clasificandoos como população cabocla ribeirinha, amalgamada por elementos da sociedade amazonense e, dessa forma, todos que estão no rio Negro são todos miscigenados. Apoiados nessa concepção, eles sustentam que não há motivos para a demarcação de terras para índios, porque no rio Negro não existem indígenas "selvagens".

O movimento indígena combate firmemente esse tipo de posicionamento, demonstrando o quanto a sociedade nacional brasileira históricamente ignorou a visibilidade dos indígenas, para quem os pressupostos das suas identidades e o entendimento do territorio se fundam em um conjunto amplo de conhecimentos que ultrapassam a esfera da fisicalidade:

\begin{abstract}
Sim, nós indígenas somos misturados sim, nenhuma raça é pura, desde os tempos dos antigos a gente vive se misturando, basta observar em nossas histórias contadas pelos mais velhos para perceber que sempre teve essa mistura aquí no rio Negro. A gente descobre e inventa as coisas. Agora não se pode afirmar que todo mundo aquí no rio Negro é indígena. Nós indígenas somos iguais as mudas de maniwa, que se espalha por todas as partes, porém na roça sabemos diferenciar as ramas uma das outras, é igual gente. As mulheres sabem que Muito bem disso tem olhos apurados. Em Santa Isabel tem muitas pessoas que nasceram a partir do gomo (broto) da maniwa, mas que não estão mais no seu local debido, que é a roça. Muitas pessoas se transformaram em caraiu, mas mesmo assim muitos indígenas ainda estão firmes, plantados em seus lugares e temos a nossa diferença. Que está ligada aos nossos antepassados, dos nossos biavôs. Si todos na Amazonia são indígenas, então que venham engrossar o nosso movimento e ajudem a demarcar a proteger as nossas terras. Ma nã tudo é ao contrário, os caraiu não pensam no coletivo, senão aumentando seu patrimonio explorando nossas terras. Queremos nossas terras para garantir o nossso sustento e manter nossas tradições, manter nossas hstórias, recordar os tempos dos antigos. Aquí no rio Negro, por onde você andar você vai encontrar coisas ou marcas dos nossos antepassados. A terra é para viver na coletividade, não para usurpar e a forma que a gente usa a terra é diferenciado. (Carlos Wa'ikhen, Pira-Tapuia, Barcelos, septiembre de 2014)
\end{abstract}

Se observa que a principal questão é a garantía de um territorio considerado de ocupação tradicional. Os indígenas rionegrinos se consideram herdeiros de um território cuja fundamentação remete aos tempo da subida da cobra-canoa ou cobra-grande, que percorreu uma vasta região alocando povos e seus respectivos territórios.

\title{
Sociocosmologias e os povos indígenas do Rio Negro
}

\begin{abstract}
Assim como os rios são necessários para os peixes, as histórias de nossos parentes antigos são para nós indígenas, tudo o que foi dito por eles é importante e ninguém vive separado, apesar de ser muito antigo, ainda tem gente-peixe, tem a cobragrande não é todos que sabem, mas essas gentes controlam e estão sempre por aqui do seu jeito. Esse tipo de gente não desaparece, pelo contrário, elas estão bem presentes, apesar de se irritar com o barulho do motor, do cheiro da gasolina. Muitas outras gentes vivem com a gente. Tudo isso já era conversas dos nossos primeiros parentes. Ninguem se separa dessas coisas. (Antonio Buyawaçu, ancião baré).
\end{abstract}

Os povos do rio Negro de maneira singular e sobre os seus artificies revelam uma predisposição para contar como compreendem o seu mundo e como a memória armazena modos de conhecimentos que são atualizados e externados 
por diferentes vias, dentre as quais as narrativas que articulam eventos de época remota às transformações dos tempos atuais.

A narrativa do ancião baré acima foi de fundamental importância para reforçar a ideia de quanto as cosmologias desempenham papeis fundamentais no cotidiano dos povos indígenas do rio Negro. As narrativas são apresentadas de maneira geral com pequenas divergências, mas é sabido que existe uma força "centrípeta" onde o núcleo sofre poucas variações, como no caso das narrativas da canoa-cobra e do jurupari e do kuwai muito comuns na região em estudo. As conversas que giram em torno dessas narrativas são tematizadas na forma de sucessivos deslocamentos espaço-temporais, através dos quais a memória social articula os eventos do período de transformação mítica àqueles que já fazem parte de trajetórias históricas particulares cada grupo.

$\mathrm{Na}$ visão dos grupos tukano, por exemplo, o assentamento do rio Uaupés se deu através da jornada da cobra-canoa dos antepassados, que em seu ventre trouxe os ancestrais indígenas para a cachoeira de Ipanoré, localizada no meio curso do Uaupés, de onde partiram para a terra através de um buraco existente em uma de suas lajes. De lá, eles se separam e foram, cada um, para encontrar seu próprio lugar. (ANDRELLO, 2005, p. 07)

Nas narrativas11 de origem dos Baré, as alianças, as misturas interétnicas e a facilidade de se relacionar com os outros, através da guerra, do comércio entre outras situações são explicadas pelo fato de dois homens primordial, Kurucui e Baburi ter protagonizado uma querela que dividiu o grupo nos primeiros tempos após a transformação. A partir de então, os grupos passaram a fazer guerra entre si e com outros grupos indígenas da região, com o objetivo de aumentar seus respectivos contingentes, ampliando as alianças, o comércio e a expansão do seu território. Dessa maneira, a vida dos Baré foi marcada por encontros diversos com os "outros"; ocasionadas por fissões e fusões, por uma dinamicidade sócio-espacial muito intensa. Esses fatores conotam situações ambivalentes para o coletivo baré, por exemplo, percorrer por um caminho em direção ao mundo dos caraiu, conotando ambivalências tais como, "civilizados" e "não civilizados", cristãos e caboclos, Baré e caraiu.

No rio Negro, observamos uma forte mobilização na construção de um passado que reafirma o poder do xamanismo, a construção das pessoas e as origens dos povos, bem como a elaboração de um território descontínuo, mas sistematicamente entendido entre eles, expresso especialmente em sua narrativas. Foi exatamente por causa do potencial das narrativas rionegrinas que encontrei durante as investigações de campo, instrumental mnemônico que explicava claramente a configuração atual do território através de atualização mítica demonstradas nas narrativas. Os indígenas afirmavam com veemência de a configuração do território não precisam está no papel desenhado, mas na cabeça das pessoas que nasceram no rio e que mantêm laços múltiplos e peculiares com seus respectivos territórios.

Nós não precisamos de papel e lápis para desenhar nosso território, tudo que tem aqui tem uma pitada dos nossos antigos, assim eles diziam. Eles têm muitas coisas que vocês do governo não vêem, mas para nós está cheio em nossos pensamentos, no nosso corte, no igarapé, nos peixes que comemos; na maneira de animais. A cobra-grande que nos tempos dos antigos deixou cada um em seu canto, mas a

${ }^{11}$ A narrativa ressalta o seguinte: nessa cachoeira Kurucui e Bururi desentenderam-se e brigaram muito entre si, por isso resolveram separar-se, ficando Kurucui de um lado e Buburi de outro lado do rio. Essa separação acabou provocando desobediência às regras de Punaminari, que ordenou ao povo não se misturar com outros grupos, porém Kurucui e Baburi acharam que para pode aumentar os seus grupos tinham que ter muitas mulheres. Foi quando eles guerrearam com grupos menores para tomar suas mulheres. (Braz França Baré, comunicação pessoal, comunidade de Canafé, margem direita do Rio Negro) 
gente não é filho de cobra não, os antigos usaram ela para chegar até aqui no rio Negro, porque ainda não tinha inventado a canoa, a canoa é dos baré antigo que foi o primeiro indio no rio Negro a ter canoa, sabe? Uns dizem que foi caraui que emprestou, sei não (...). A gora a gente tem canoa, a cobra-grande não deixou mais a gente, ela mora aqui também. (Genésio Gereba, Rio Negro, 2014)

A narrativa designa a cobra-grande como um ser plural de uma única representação: ela foi objeto de navegação, gente com quem os indígenas convivem, gente que ordenou o território e é compreendida como uma figura múltipla. Nesse contexto, pecebemos que as narrativas da cobra-grande e outras subsidiava traçar o território operando em conjunto como outros elementos não oratórios, por exemplo, desenhos da icnografia e uma série marcas intencionais presentes na paisagisticas que fogem diante dos olhos dos outsiders além do rio Negro.

\section{No rastro da cobra-grande: cosmologias e territorialidades}

As narrativas referentes à cobra-grande no contexto do rio Negro têm como ponto central, os processos de transformações que ocorreram, quando se deu a passagem da "cobra-canoa" por várias localidades ${ }^{12}$. No interior da "cobra-canoa", a tripulação era formada por vários tipos de "gentes", dentre os quais os ancestrais ainda não completamente humanos de todos os povos que iriam habitar por toda a bacia do rio $\mathrm{Negro}^{13}$. Porém, de acordo com Andrello (2006, 2014), nem todos que estavam abordo vieram a passar pelo processo completo de humanização. Esse contexto narrativo está imbricado diretamente com a constituição do território rionegrino e da configuração sócio-espacial dos povos locais. Tendo como referencial as narrativas em torno da cobra-grande, procuro nas linhas abaixo, demonstrar as concepções de território e suas territorialidades. No contexto atual, existe uma sobreposição de conhecimentos referentes ao território. Por um lado, os indígenas que compreendem seguindo o "rastro da cobra-grande" e outras sociocosmologias e, por outro lado, o Estado que impõe um território rechaçado a fronteiras e limitações.

No ano 2000, o movimento indígena, através da Federação das Organizações Indígenas do Rio Negro - FOIRN protocolou junto à FUNAI, a solicitação emergencial para demarcação das terras indígenas da região do Médio Rio Negro, pois as lideranças políticas indígenas alegavam que região em tela é um território de ocupação tradicional indígena e que no conjunto das Terras Indígenas já demarcadas na região, faltava garantir ou recuperar as terras do Médio Rio Negro consideradas por eles como de suma importância para reprodução física e cultural.

Durante os estudos de Identificação e Demarcação de que participei ocorridos $^{14}$ entre 2010 a 2015, os indígenas foram enfáticos em elencar que eles ti-

\footnotetext{
${ }^{12}$ Alguns dos povos indígenas da bacia do rio Negro foram trazidos do mundo espiritual para esse mundo que hoje habitamos no ventre de uma grande cobra que começou sua jornada no Lago do Leite (onde hoje está localizada a Baía da Guanabara, na região Sudeste) e foi subindo pelo litoral. Toda vez que ela saía do rio subterrâneo, por onde estava transitando, para respirar, deixava um pedaço da humanidade. Assim foi até a sua chegada à região do Uaupés, na Cachoeira de Ipanoré, onde o restante da humanidade "desembarcou", dando origem aos povos que lá vivem. Ver Andrello (2006), Lasmar (2006).

${ }_{13}$ Para os Tariano, o mito da cobra-grande está diretamente relacionado à questão espiritual. Para esse povo do Alto Rio Negro, os Locais de transformação mítica, que marcam as etapas finais do processo de gestação da humanidade, são, ao mesmo tempo, locais de separação dos diversos grupos que hoje vivem na região. Ver Andrello (2006, 2012, 2014)

14 Vários GTs foram constituídos pela FUNAI para realizar os estudos, porém muitos relatórios não foram aprovados pelo órgão indigenista oficial por apresentar vários equívocos e incorreções, sobretudo, o relatório coordenado pelo Edward Luz, que atesta a não existência de indígena na região, considerando que toda população rionegrina está
} 
nham todo o território mapeado na cabeça e não necessitavam do papel ${ }^{15}$, embora tendo consciência que boa parte do território do Médio Rio Negro estava fatiada entre os comerciantes, os empresários do turismo e os empreendedores da pesca esportiva. Esta situação causou uma grande querela, porque do ponto de vista indígena, a área continuava pertencendo aos seus ancestrais e, portanto, a eles também. Dessa maneira, não se sentiam na obrigação de estar atestando o reconhecimento do território que a eles pertencem.

Todavia, os indígenas propuseram suas metodologias para demonstrar o território e os processos de territorialidades. Sugeriram que a partir do "rastro da cobra-grande" poderia visualizar com precisão, o território deles. Escolheram os principais chefes de grupos domésticos para percorremos por algumas localidades, apontando alguns marcos físicos que de acordo com os chefes, ratificavam vínculos de ancestralidade e da presença dos primeiros humanos e povos na região, embora na consciência dos interlocutores indígenas de comunidades povos diferentes, não restavam dúvidas sobre os processos de descontinuidade tanto da configuração do território, quanto das narrativas que eles apresentavam.

A narrativa que mais se tornou evidente e que apareceu no repertório de todos os interlocutores foi quando da subida da cobra-canoa abordo de "gentes" em processo de transformação iam se fixando em determinadas localidades, no entanto, observa-se que tudo indica que alguns povos já haviam passado pelo total processo de humanização, como Mira-Boia (gente-cobra), um homem que viajava sem par (companheira) dentre todos os tripulantes da cobra-canoa. Quando a canoa passa pela foz do rio Negro, Mira-Boia avista em uma das margens um grupo de mulheres, que seduziram-no a pular. Mira-Boia nadou até a margem para se juntar ao clã das mulheres que já havia passado pelo processo de transformação. A narrativa indica que Mira-Boia é um dos primeiros ancestrais dos Baré a passar pelo processo de transformação, sendo que a união dele com uma mulher do grupo (Tipa) resultou no primeiro processo de territorialização dos Baré, grupo que passou a povoar o rio Negro do montante a jusante

Esse fato de maneira geral foi considerado como uma quebra de regras, pois o que acontecia durante o percurso era que em todo lugar em que se territorializassem "gente" que havia passado pelo processo de transformação de "bichos" para humanos, os viajantes da canoa dos ancestrais permaneciam por um bom tempo, até que aqueles que estavam sendo deixados se acostumassem em seus respectivos lugares.

A viagem da canoa ancestral inicia no do Lago do Leite, provavelmente na baia de Guanabara, percorrer por todos os continentes, findando a trajetória nas cabeceiras do rio Negro. Cada "gente" (Mira-Boia, We'ê-masa, Wai-Masa, Yebamasa entre outros), reconhecem seus respectivos lugares de origem, assim como identificam marcas físicas presentes nas paisagens, como serras, petróglifos, cachoeiras, enseadas, encostas, igarapés, entre outras. Isso indica que as narrativas funcionam como semântica chave e interpretativa que orientam os indígenas a produzir um conjunto de conhecimentos que envolve taxionomias de lugares, locais sagrados, fisiologia paisagística entre outras.

Dessa maneira, os sinais físicos e simbólicos deixados pelos ancestrais fazem eco aos rastros deixados pela cobra-canoa, evidenciando que o passado é

${ }_{15}$ Como enfatiza o ancião Braz França: "o papel envelhece fica pobre, as coisas que estão na nossa cabeça não, a gente perde um pouco da memória, mas não tudo, a gente lembra. O que os antigos nos ensinaram está na nossa memória, por isso nós indígenas damos mais valor ao que está na cabeça e não no papel”. 
visível nas ruínas, nos petróglifos, nas cachoeiras e, sobretudo, no pensamento. Isso faz contrapor a visão cartográfica, escalonar que tende a silenciar toda uma elaboração a priori sobre territórios e os processos de territorialidades de povos rionegrinos vivenciaram. Parafraseando um ancião baré, "o território está na cabeça e nunca apodrece" e, por isso, eles rejeitam qualquer intrusão que rechace os seus entendimentos quanto aos seus territórios, como enfatiza o ancião:

\begin{abstract}
O território do meu povo já foi definido nos tempos dos nossos ancestrais, quando eles ainda não eram gente, cristão mesmo. Antigamente toda a terra era habitada pelos animais, não existia gente humana, não existia cristão. Então nosso Deus criou um pajé forte que resolveu colocar gente no mundo. Ele conseguiu juntar todos os animais, arara, papagaio, anta, onças, todos e saiu viajando pelo mundo numa grande canoa que os antigos chamam de cobra-grande. Só que alguns animais não se transformaram em gente, por ignorância mesmo, mas tudo é gente também, mas diferente, ainda não transformado. Os primeiros povos são tudo parente dos animais, para nós indígenas, os mais velhos nos ensinam que os lugares também são dos animais, eles têm o mesmo poder que nós ou até mais. Então, a gente sabe que tudo que está no mundo não é de uma só pessoa, não é do Brasil, da Colômbia, da Venezuela, toda essa a terra, os rios, as matas foram deixadas pelos antigos para poder viver gente que se transformou e aqueles que não conseguiram virar gente. Tudo isso não está no papel, mas está na cabeça de todos indígenas do rio Negro. (Antonio Caeira, comunidade Acuacu, rio Padauiri, agosto de 2010)
\end{abstract}

As narrativas compõem premissas centrais que valorizam o pensamento, a memória mítica como fundamentais para se discutir território. Utilizado recursos metafóricos, os indígenas articulam o mito da cobra-grande de forma anacrônica a diversas situações sociais. Para muitos povos indígenas amazônicos, o mito da cobra-grande possui relação com o território, com a organização da vida e do mundo e que constitui como uma forma desses povos pensarem sua própria história. Entende-se que as narrativas coletadas durantes a pesquisa empregam um discurso mais cotidiano e partem de conjunto de histórias conectadas fornecendo diferentes campos ópticos, porém como uma força centrípeta cujo núcleo de atração é a transformação de diferentes gentes em humanos alicerçados à ordenação territorial e a hierarquia ritual e política entre povos.

\begin{abstract}
Meu avô sempre mostrou que nada nesse rio Negro acontece por acaso. Tem muita história de pessoas, animais e da nossa própria terra. Os mais velhos dizem que a terra é cinzas dos nossos antepassados, a mandioca surgiu a partir de pedaços de dedos do primeiro índio. Então tudo aqui tem a nossa marca. Veja na pedra do Espírito Santo. Tem uma marca do pé do primeiro índio do rio Negro, que criou essas coisas. Os índios de primeira parecia que tinham muita força igual a Deus. Ps primeiros que controlaram a cobra-grande para marcar nosso território. Ma não foi só ela não, teve dedo de outros bichos também. Cada povo ficou com uma força diferente, por isso que tem a diferença, tem o baré, o tariana, o arapasso, todos tipos de gente. (Joaquim Urgarte, Rio Padauiri, agosto de 2010)
\end{abstract}

Apesar das diferenças, as narrativas rionegrinas compartilham, de modo geral, uma estrutura concêntrica que Hugh-Jones (2012) salientam como uma "tradição narrativa compartilhada, distribuída entre grupos diferentes, cada qual conferindo à sua interpretação de acordo com a sua identidade específica”. Nossa tarefa não foi fazer um instigado jogo sobre os conteúdos estruturantes das narrativas, mas compreender o seu uso, rastreando os seus múltiplos entendimentos aonde quer que elas conduzam no que tange a vida, os povos, o território e a construção do pensamento em constante movimento ${ }^{16}$.

16 De acordo com uma narrativa Tukano, os brancos também faziam parte da tripulação da cobra-canoa, no entanto, Pa'mîri Pîro (gente em transformação) vai deixar os ancestrais dos brancos em outros continentes. De acordo com Maia 


\section{Algumas considerações}

O mito da cobra-grande é fundamental para entender os processos de mobilidades socioespaciais no rio Negro e a sua configuração territorial. As narrativas em volta da mito são difundidas em toda região amazônica sendo sua presença recorrente na etnologia sul-americana e em todo o Brasil indígena, além de ser encontrada também no folclore nordestino, na literatura e nas artes plásticas. De acordo com Lux Vidal (2009), as variações do mito da cobragrande de maneira geral formam um conjunto de narrativas interligadas a outros mitos amazônicos.

Verificamos no Médio Rio Negro um profundo conhecimento indígena dos diversos repertórios da narrativa da cobra-grande tanto para uso instrumental quanto simbólico, pois cobra-grande pode ser alma, espírito, mas também pode ser um pajé, um xamã. Os pajés e ou xamãs são considerados gente de suma importância para o equilíbrio social e das coisas do mundo (mata, animais, rios, etc.) e exímios conhecedores de uma geografia xamânica, pois estes pelo poder de transcendência percorrem por todos os lugares do mundo (aquático; terrestre e celestial).

Observamos como as trajetórias da cobra-canoa influenciaram diretamente as concepções para o entendimento do território e dos processos de territorialidades entre os povos do rio Negro. As referências a lugares, paisagens e uma temporalidade anacrônica se entrelaçam com potencialidades da memória de pessoas que ultrapassam a esfera da fisicalidade. Esse aspecto nos permitiu adentrar em outras esferas sociais, por exemplo, a biografia social das comunidades, sua sociogênese, as relações com os animais e as plantas, assim como identificamos espaços sacralizados, como as marcas de pegadas de Purominari, o Deus baré visivelmente observadas em petróglifos no lajeado do Espírito Santo, abaixo da cidade de Santa Isabel, destacado por um narrador.

Esse mundo de potências descrito na sociocosmologia rionegrina é manejado diferencialmente por cada narrador, porém, sem perder os pontos estruturantes que são partilhados por pessoas de sabedorias especiais, como os xamãs, os anciões, a dona de roça, o rezador, o benzedor.

Nesse sentido, as narrativas indígenas engendradas por essas pessoas se tornam referencias diferenciadas que constituem, neste sentido, lócus privilegiados para pensar o território, mas também a vida diária, o cosmo e as coisas em movimento.

Recebido em 2 de maio de 2018.

Aprovado em 20 de março de 2019. 


\section{Referências}

ANDRELLO, Geraldo. Rotas de criação e transformação. Narrativas de origem dos povos indígenas do rio Negro. ISA, FOIRN. São Paulo, 2012.

ANDRELLO, Geraldo. Cidade do índio. Transformação e cotidiano em Iauaretê. Editora UNESP, São Paulo, 2006.

ANDRELLO, Geraldo. Nossa história está escrita nas pedras. Conversando sobre "cultura" e "patrimônio cultural" com os índios do Uaupés. ANPOCS, Caxambu, 2005.

BENJAMIN, Walter. Walter Benjamin: Obras Escolhidas Volume I: Magia e Técnica, Arte e Política. São Paulo: Editora Brasiliense, 1985.

CABALZAR, Aluisio. Filhos da Cobra de Pedra: organização social e trajetórias tuyuka no rio Tiquié (noroeste amazônico). São Paulo, Editora da Unesp/ISA/NuTI, 2009.

CHERNELA, Janet. Vital souls: Bororo cosmology, natural symbolism, and shamanism. Tucson, Arizona, University Arizona Press, 1996.

ENGRÁCIA DE OLIVEIRA, Adélia. Depoimento dos Baniwa sobre a relação entre índios e civilizados no rio Negro. Boletim do Museu Paraense Emílio Goeldi. Belém, 1979.

GALVÃO, Eduardo. Aculturação indígena no rio Negro. Paz e Terra, Rio de Janeiro., 1979.

GALVÃO, Eduardo. Santos e visagens. Um estudo da vida religiosa em Ita, Amazonas. São Paulo: Companhia Editora Nacional, 1955.

GOLDMAN, I. The Cubeo: Indians of the Northwest Amazon. Urban, The University of Illinois, Press, 1963.

HILL, Jonathann \& Wright, R. Time narrative and ritual: historical interpretation from an Amazonian society. In HILL, Jonathann. (Org.). Rethinking History and Myth. Indigenous South American Perspective on the past, 1988.

HUGH-JONES, Stephen. La palma y las Pléyades. Iniciacíon y cosmologia en la Amazonia noroccidental. Ediciones Universidad Central, Bogotá, 2013.

HUGH-JONES, Stephen. Escrever na pedra, escrever no papel. In ANDRELLO, Geraldo. (Org). Rotas de criação e transformação. Narrativas de origem dos povos indígenas do rio Negro. ISA, FOIRN. São Paulo, 2012

LA CONDAMINE, Charles-Marie de. Viagem pelos amazonas, 1735-1745. Rio de Janeiro. Editora Nova Fronteira/Edusp, ([1745]1992).

LASMAR, Cristiane. De volta ao logo do leite. Gênero e transformação no Alto Tiquié. Editora da UNESP, São Paulo, ISA, NUTI, Rio de Janeiro, 2005.

MAIA, Moisés \& MAIA, Tiago. O conhecimento de nossos antepassados. Uma narrativa Oyé. São Paulo/São Gabriel da Cachoeira: FOIRN/COIDI (ISA/H3000), 2004

MAIA FIGUEIREDO, Paulo R. Desiquilibrando o convencional: estática e ritual com os Baré do Alto Rio Negro (AM). Tese de doutorado, PPGAS-UFRJ, Museu Nacional, Rio de Janeiro, 2009. 
MELO, Juliana. Identidades Fluidas: ser e perceber-se como Baré (Aruak) na Manaus contemporânea. DAN, PPGAS, UnB, tese de doutoramento, Brasília, 2009.

NASCIMENTO, L. A. S. Patrões, fregueses e donos. Economia e xamanismo no Médio Rio Negro. Tese apresentada ao Programa de Pós-Graduação em Antropologia Social da Universidade de São Carlos. 2017

NASCIMENTO, L. A. S. Relatório de Fundamentação Antropológica da região do Médio Rio Negro. FUNAI, CGID, restrito. 2014

NIMUENDAJÚ, Curt. Textos Indigenistas. Org. SUESS, P. São Paulo, Ed. Loyola. 1983 .

REICHEL-DOLMATOFF, Gerardo. Desana: Simbolismo de los Indios Tucano del Vaupés. Bogotá. Universidad de Los Andes, 1990

STRADELLI, Ermanno. Lendas e notas de viagem. A Amazonas de Ermanno Stradelli (1887-1926). Martins Fontes. São Paulo, 2009.

VIDAL, Lux). A Cobra Grande: uma introdução à cosmologia dos povos indígenas do Uaçá e Baixo Oiapoque - Amapá. Rio de Janeiro: Museu do Índio, 2009

WALLACE, Alfred R. Viagens pelo Amazonas e Rio Negro. Edições do Senado Federal, Brasília, [1853] 2004.

WRIGHT, Robin M. O tempo de Sophie: história e cosmologia da conversão Baniwa. Em Transformando os Deuses. Os múltiplos sentidos da conversão dos povos indígena no Brasil. Campinas, SP, Editora da Unicamp, 1999.

WRIGHT, Robin M. Aos que vão nascer. Uma etnografia religiosa dos índios Baniwa. Tese de Livre-Docência, IFCH, Unicamp, Campinas, 1996

WRIGHT, Robin. História indígena do Noroeste da Amazônia: hipóteses, questões e perspectivas. In M. Carneiro da Cunha (org.) História dos índios no Brasil. São Paulo: FAPESP/Companhia das Letras/SMC. 1992

WRIGHT, Robin M. Cosmos, self and history in Baniwa Religion: for those unborn. USA: University of Texas Press, 1998. 